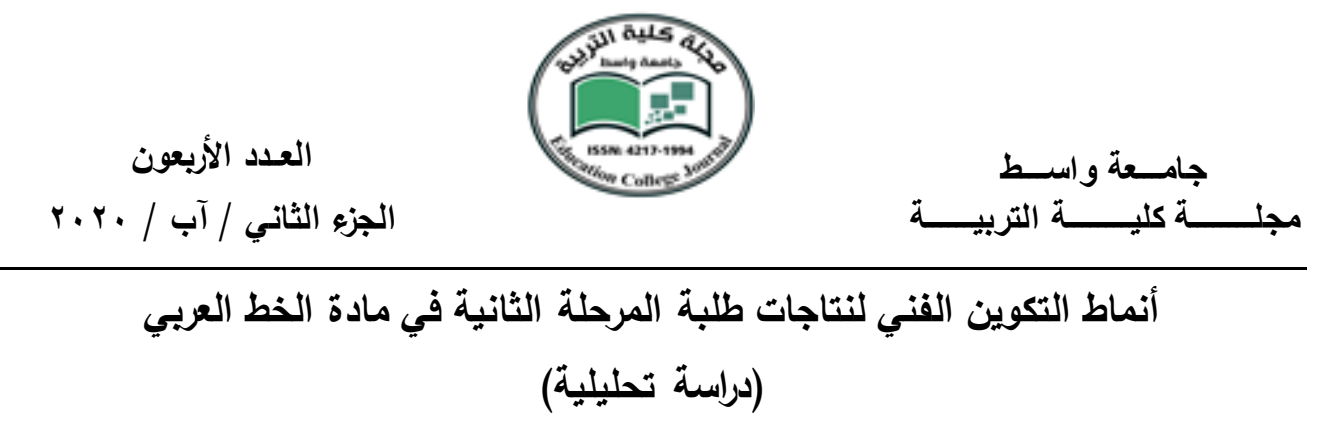

م.د جواد كاظم محمد

قسم التربية الفنية / كلية الفنون الجميلة

جامعة واسط

jkadhim@uowasit.edu.iq
م.م حسين رشك خضير

قسم التربية الفنية / كلية التربية الأساسية

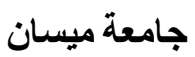

alfananhassen@gmail.com

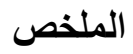

هدف البحث الى الكثف عن أنماط النكوين الفني لنتاجات طلبة المرحلة الثانية في مادة الخط

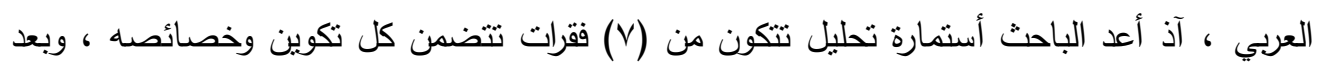

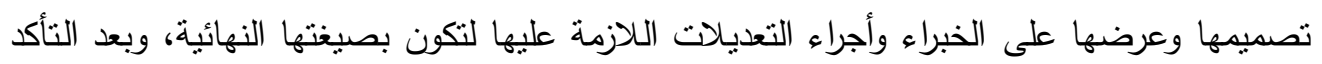

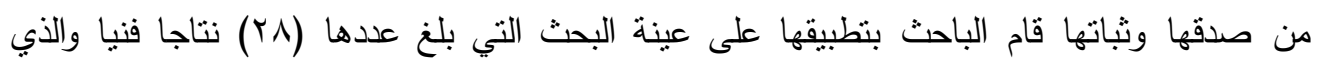

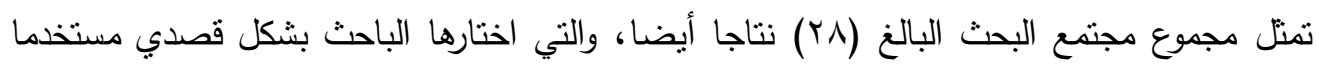

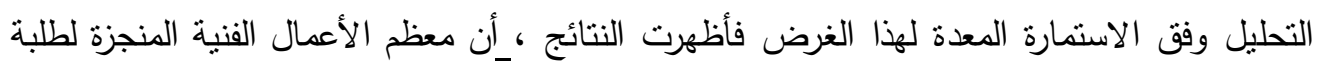

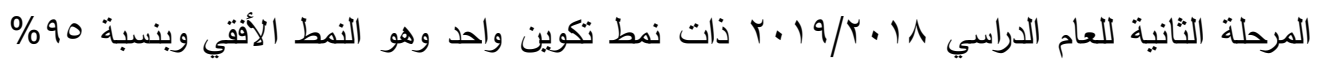
وبنسبةه\% ذات نمط نكويني دائري. ومن ذلك استتنج الباحث الى أن المستوى المعرفي الضعيف

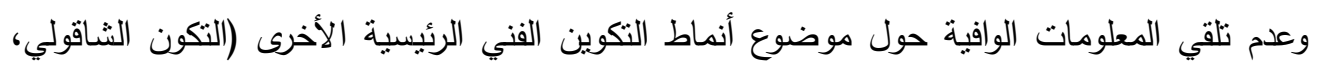

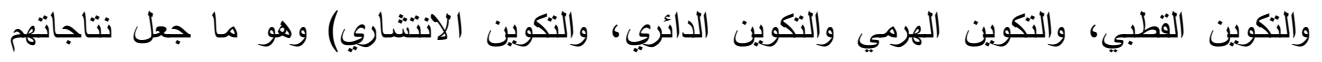

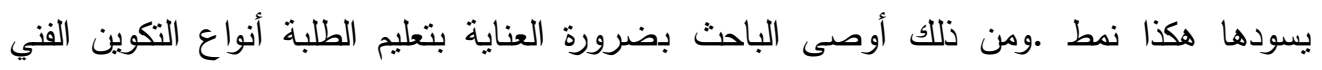

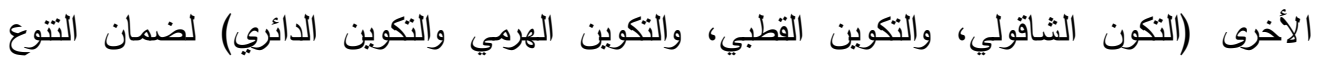
والتتكيل لتحقيق الجمال الفني للخط العربي ويكون ذلك من خلال جطله من ضمن مفردات مادة التهب

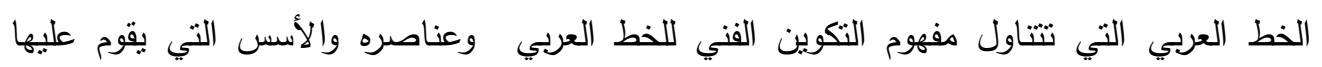
وكذللك أنماط التكوين التي هي هدف البحث. الكلمات المفتاحية: أنماط التكوين الفني ، طلابة المرحلة الثانية ، الخط العربي 


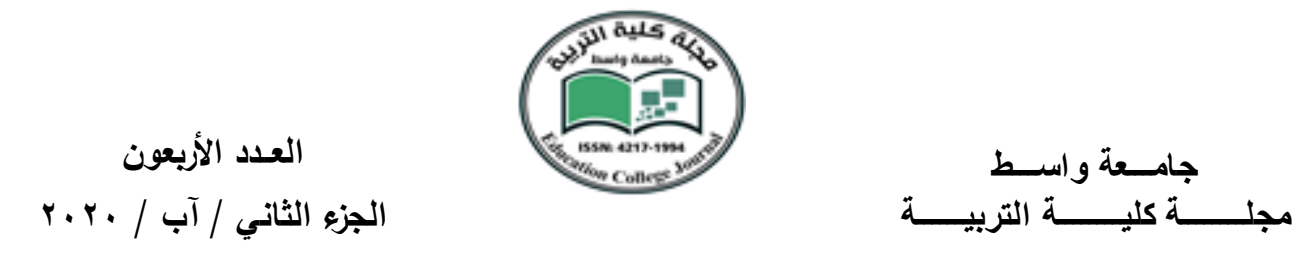

Artistic Formation Styles For Second Stage Students Productions in Arabic Handwriting ( Stylistic Study)

\begin{abstract}
The aim of the research is to reveal of artistic formation styles for the second stage students in the subject of Arabic Handwriting. The Researcher adopted analysis application form consists of $(7$ items) concluding each formation and its features, after made its design and showed it to the experts ; some holding modifications are completed to appear finally. After the researcher assured from its credibility and its fixation, he applied it on the sample of the research that counted 28 artistic production. These sample of the research was chosen by the researcher intentionally using the analysis according to the adopted application form for this purpose .The results appeared that the most of well-done artistic works for the second stage students in 2018- 2019 are one formation style (the horizontal style) in $95 \%$ and in $5 \%$ in circular formation style. The causes of these results get back to the cognitive weakness level and there were no enough information about the others main artistic formation styles( level formation, polar formation, pyramidal formation and circular formation) for guaranteeing the variety and formation to achieve artistic gratefulness to the Arabic Handwriting; to achieve that can be included in the syllabuses of the subject of the Arabic Handwriting. This subject has the principle of artistic formation of the Arabic Handwriting and its components that based on it and the formation styles as well that are the aim of the research.
\end{abstract}

Keywords: Artistic Formation Styles, Second Stage Students, Arabic Handwriting 
أن الحضارة ظاهرة تتمنل في المجتمع الإنساني كما تتمثل في حياة الإنسان الفكرية ومسائلة المادية

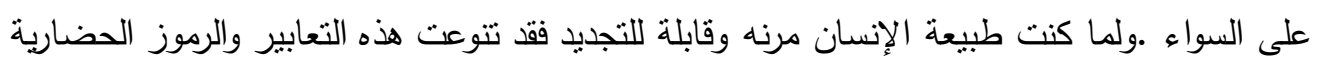
ولاسيما الفنية ومنها، وكما هو معروف ان الخط العربي هو رمز حضاري وجدناه بعظم الأمة

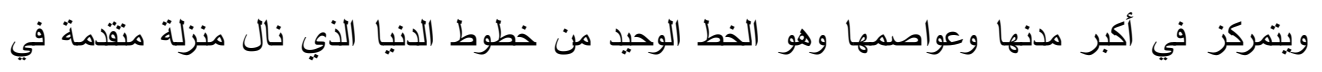

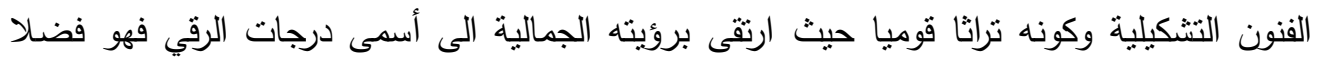

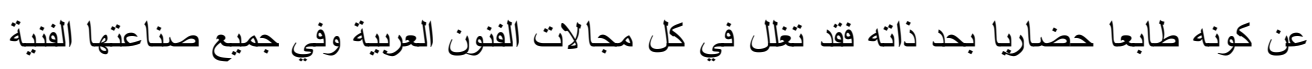
والتطبيقية، ولأهية هذا النوع من الفن وكونه يمثل وسيلة اتصال مهمه تعكس الواقع الثقافي لأمتتا

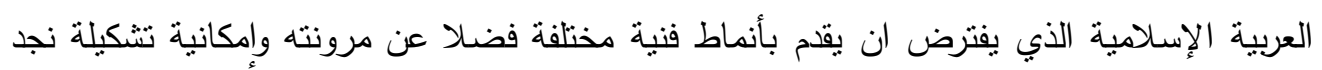

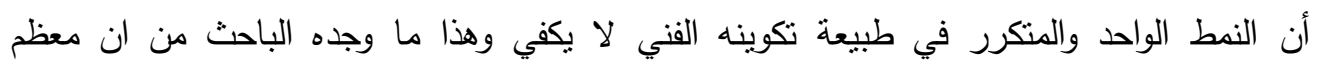

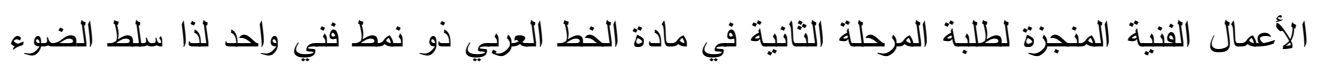

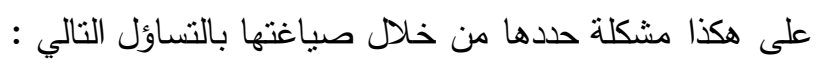

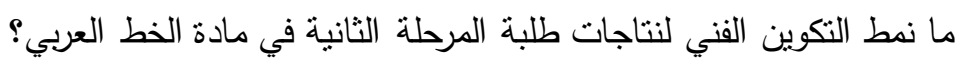

\section{أهمية البحث:}

ا ـ يسهم البحث بتحديد تتوع النكوينات للإعمال الفنية المنجزة لطلبة المرحلة الثانية في

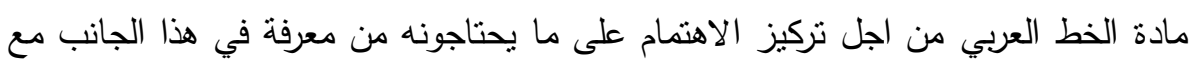

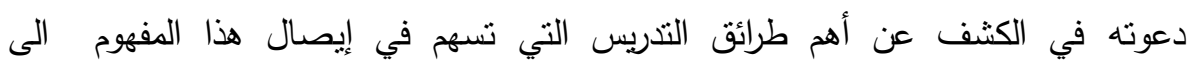
المتعلمين. r. قد يسهم البحث بتوعية الجانب الفكري والتطبيقي في هذا المجال لاسيما في الكليات

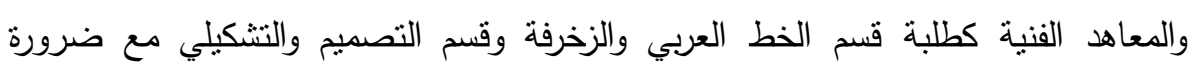
توظيفه كمتغير له من الأثر ما يسهم في البعد الجمالي والنفعي لنتاجاتهم الفنية.

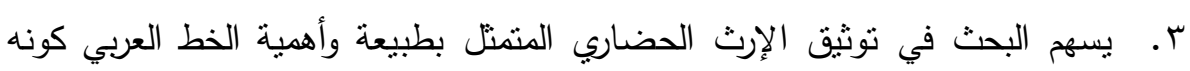
واجهة ووسيلة ومنفة من المنافذ الذي بعكس الواقع الثقافي لأمتنا الإسلامية. 


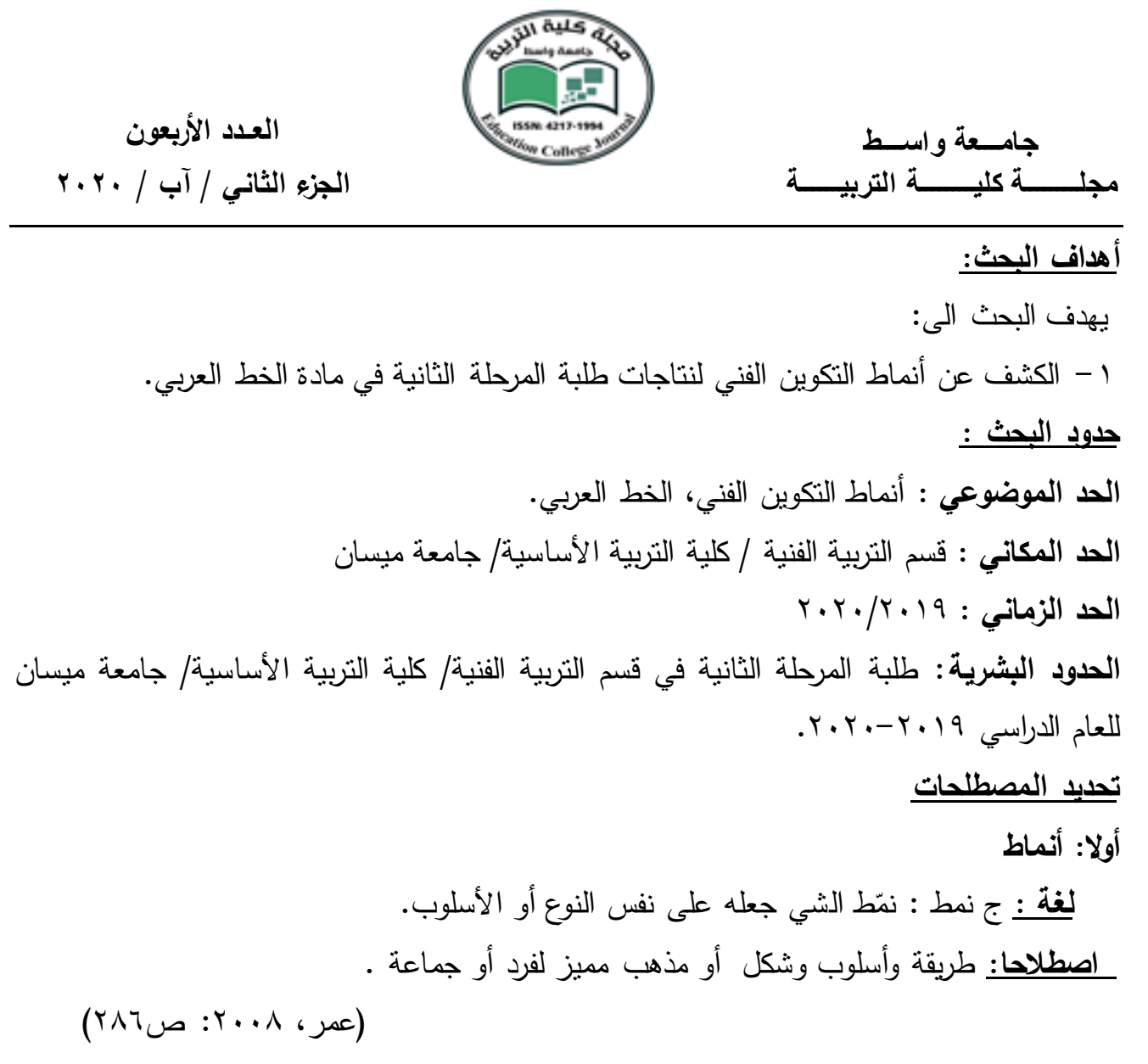

ثانيا التكوين الفني:

عرفه (فريدريك، بو 199) بأنه: عبارة عن عملية ترتيب وتنظيم العناصر بهدف خلق وحدة مفاهيمية.

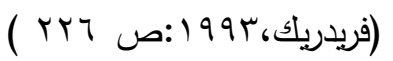

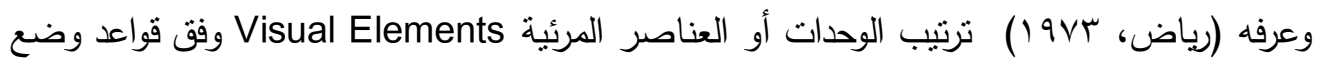

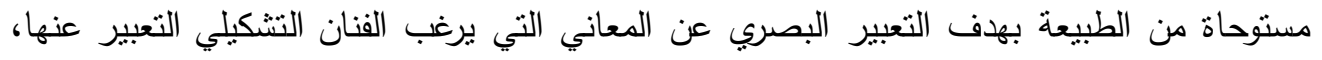

$$
\text { (رياض، 9Vr 19 ص 9 9) }
$$

أنماط التكوين الفني: هي أنواع أو أساليب ترتيب وتنظيم العناصر التثكيلية للخط العربي بهذف

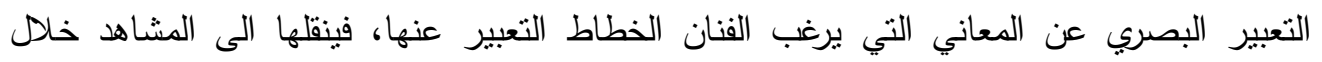
العمل الفني للتعبير عن فكرة أو موضوع ما. الفي برغ الكنان 
العدد الأربعون

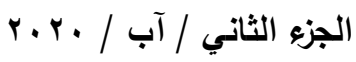

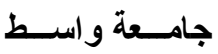

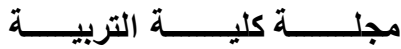

الخط العربي اصطلاحا:

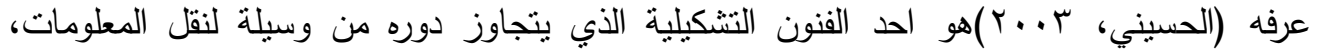
ليصبح غاية متكاملة روحانية جمالية، وتجريدية المفهوم، وهو مهيأ أصلا - مدلولا وتركيبا- لتأدية

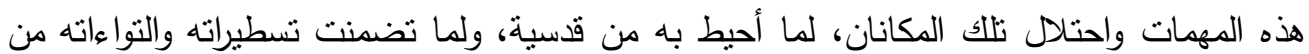
حركة إيقاعية وتركيب منوازن ومتتاغم.

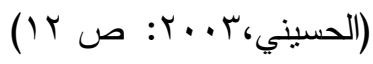

الخط العربي إجرائيا: هو فن الكتابة العربية بمختلف أنواع الخطوط كالخط الكوفي وخط الرقعة وخط النسخ والخط الديواني وغيرها من أنواع الخطوط الأخرى الذي يعنبر كجزء من المواد التعليمية للمرحلة الثانية في أقسام التربية الفنية في كليات التربية الأساسية في الجامعات العراقية.

الفصل الثاني/ الإطار النظري

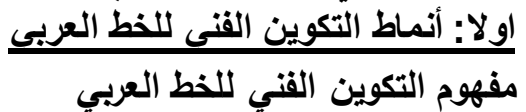

الحديث عن التكوين الفني في الخط العربي هو حديث عن أهم مـا يحقق عملية الاتصـال من خـلال الفن بين الفنـان الخطاط والمنلقي ، لأنـه بدوره يمثنل محتوى الرسـالة وأسلوب أو نمط تكوينها، وان المرسل بطبيعة الحال ان كان مـا يصدر عنه قد تم توظيفه بشكل صحيح ودال حتمـا ستكون قراءة رسالته من قبل المتلقي صحيحا ومنميزا بالسهولة والوضوح قد يصل من خلاله الى فهم فحوى الرسالة وإبعادها النفعيـة ومقاصـدها الجماليـة، أمـا أذا كان العكس فـأن عملية الاتصـال تكون فاشـلة وغير محققة للغرض الذي أعدت من اجله، فالتكوين الفني للخط العربي بشكل عام هو القالب الشكلي الذي يقدمه الفنان الخطاط بصياغة تعبر عن هدفه من خـلال وضع وحدات منجزه الفني بطريقة ذو نمط هوي معين، فمفهوم التكوين الفنـي للخط العربـي لا يختلـف عن غيـره في أنـواع الفنون الأخـرى كالرسـم والنحت والمسرح وغيرها أو كما يرى (رسكن) بشكل عام : أنه وضع عدة أشياء معاً، بحيث تكون في النهايـة شيئًاً واحداً، وإن أيـاً من هذه العناصـر يسهر مسـاهمة فعالة في تحقيق العمل النهائي بحيث يكون كل شـيء في موضـع محـد ويـؤدي الدور المطلـوب والحيوي مـن خـلال علاقته بالمكونـات

$$
\text { (ستولنيز، جيروم،. ؛ }
$$


العدد الأربعون

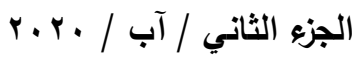

لا ان اختلافه في طبيعة التمييز الذي يتميز بـه هذا الفن الذي تشكل وحدته الصغيرة هي الكلمة ومن ذلك يمكن تعربفه بأنه: بأنهه عمليـة تتظيم وتآلف وبنـاء تلك العناصـر المرئيـة (الحروف والكلمـات والمقاطع والثكل) بهدف خلق وحدة ذات تعبير فني وفق منهج جمالي معين) •

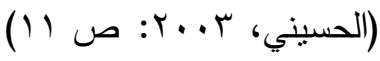

ومن هذا نفهم ان فن الخط العربي يعنمد في بلاغة تصويره على مراعاة الأسس الفنية والمبادئ التي تحكم طبيعته الجمالي أي على طبيعة نوزيع العناصر الداخلة في تشكيلة وكذا يعتمد على النمط الذي يميز ترتيب هذه العناصر ويحدد أسلوبها، كما انه من الأمور المهم التي تميز تكوين فن الخط العربي هو أنه بوجود التكوين لا يضفي معنى بقدر ما بضفي قيمة لهذا النوع من الفنون على عكس الفنون الأخرى التي قد تفقد معناهـا أن لم تراعي المبادئ أو الأسس التي يقوم عليها الحكم الجمـالي وتثبيت المعنى. عناصر التكوين القني للخط العربي

يتكون التكوين الفني للخط العربي من مجموعة من العناصر التي ذكرها الحسيني وهي كما يلي : ا-النقطة : النقطة في تكوين الخط العربي فقد خرجت عن المعنى الهندسي واللغوب الى عدة معاني اصطلح عليها النقط الإعرابي وكذللك النقط الاعجامي والنقطة المستخدمة كوسيلة، أو كوحدة قياس الخطوط المنسوبة ذات الإبعاد المتتاسبة و المتتاسقة لدى الخطاطين، وقد تكون بأشكال مختلفة

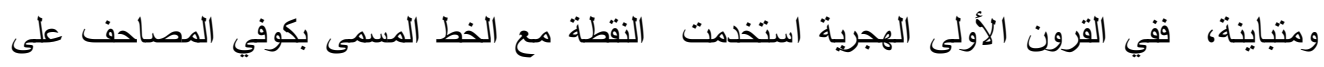
شكل أو بهيئة خطيط رفيع ، وفي خطوط أخرى كالخط المغربي، و الأندلسي الكوفي الحديث بشكل

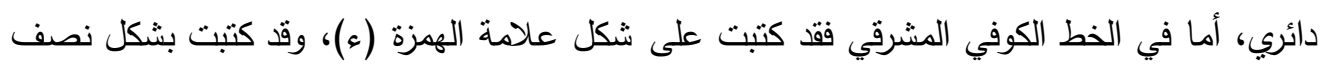
مربع مائل كما في خط الرقعة. وأيضا من أشكال النقطة المختلفة والتي تكون بحسب نوع الخط الذي يمنلها (مربع معيني كامل، ومربع مقعر، ومنوازي مستطيلات، ومربع منكامل غير مائل، ) وقد تأتي بأشكال مختلفة ومتنوعة مع الخطوط الأخرى كالخط الحر، أو ما يسمى بالخط الكيفي وقد تكون

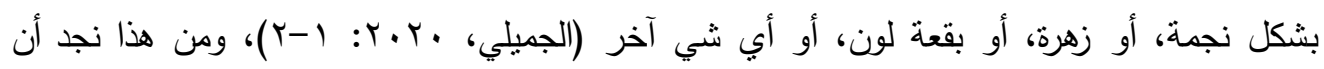
النقطة لها من الأهمية ما يجعلها تتجاوز وظيفتها كاعجام لبعض الحروف العربية الى إمكانية اعتبارها عنصرا مهما في أشكال الخطوط وقاسما مشتركا أيضا بين الحروف، اذ تأخذ كقياس لحروف لئ الخط العربي ويصبح الأمر متعذرا في إيجاد بديل مناسب لهذه الوحدة القياسية (الخطيبي، .91 1: (0) ويعد بعض الفنانين الخطاطين الى استخدام النقطة بإحجام مختلفة مبالغ فيها في التكوينات 
العدد الأربعون

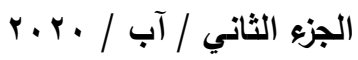

الخطية، اذ يعد ذلك معالجة فنية ذات تحول بنائي يضفي طابعا تعبيريا مضافا الى جانب التمسك بقواعد الخط العربي وأصوله الموضوعة. r -الثكل في تكوين الخط العربي: الثكل في الخط العربي يمنل عنصرا مهما من عناصر التكوين الذي تحدد معناه وتتبت وجوده واستقلاليته بصفته فن الخط العربي، وقد يكون حرفا، وقد يكون كلمة، وقد يكون عبارة تشكل بمجملها شكلا محدا ثم ما يميز الثكل في الخط العربي من (حرف وكلمة وعبارة) هو طبيعة تشكيلها ووضعها الذي يخضع للتنوع في أساليب هذا الفن فنجد فنجده يختلف من الخط الكوفي الى خط الرقعة ومن الخط الديواني الى خط النسخ وهكذا، على عكس الإشكال في التكوينات الفنية للفنون الأخرى التي لا نجد فيه حرية التصرف في هيئة الثكل نفسه بحيث لا يفقد معناه ولا يذهب بعيدا عن هيئته التي وجد عليها، ومن هنا نجد في للعبارة الواحدة أكثر من شكل هل يقدمه الفنان كتعبير بصري يمكن ان يصل الى غايته المعنوية، وهذا ما أثار اليه (الزفتاوي، جهوه ( ) في كون ذلك "لم تقتصر التحولات البنائية في الإعمال الفنية على النقطة أو الحرف أو الكلمة أو المقطع الجملي فحسب، وإنما شمل كل التكوين الفني ، ويكون ذلك عندما يكتب التكوين بصور عده وينص واحد ولا أكثر من خطاط، وهذا يذل على الثراء الكبير الذي يتمتع به فن الخط العربي وخاصة التكوين الخطي الذي يمثل مرحلة منقدمة ونتيجة لما أنتجه الخطاط بعد ان امتلك أدواته الصحيحة، بله واكتملت خبرته الفنية من خلا إتقان إثكال حروف الخط العربي وقواعده ومعرفة خصائصه، كونها تمنل عناصر بنائية تشكل عوامل وحدة في بناء اللوحة الخطية، وأن الحروف العربية ذات مواصفات فنية عديدة، يمكن من خلالها ان تكتب بصور عديدة أيضا على أساس متنوع وفي نلك يقول الكندي- فن الكتابة العربية من لها من التصرف والتتوع ما لا يمكن في غيرها.

$$
\text { (الزفتاوي، }
$$

r -الخط في تكوين الخط العربي: الخط في التكوين يمثل صورة الحرف والذي بمجموع الحروف يشكل صورة الكلمة وصور المقطع الجملي أي بمعنى يمثل شكل التعبير المراد والمقصود للفنان وعن طريق الخط تتحدد "نمط ونوع الخط العربي كفن وكذلك حركة واتجاه الخط في التكوين وطبيعة التشكيل البنائي للحروف وكذللك علاقات التجاور بين عناصر وهذه كلها مجموعة من القواعد يعد تلبيتها كدلالة بصرية يمكن إدراكها من خلال ما توحي به وتؤكده مجموعة الأحاسيس الإدراكية من خلال ما يسمى الإدراك والشعور للمتلقي، وتختلف تلك الادراكات تبعا لاختلاف الهدف أو الرسالة المطلوب إيصالها من قبل المصدم أو الفنان والتي من أمتلنها:( الحركة والجمود)و (الصلابة والليونة) و و والاستقرار والنطاير) و الثبات والزعزعة والنقلب) و (الاستمرار والرسوخ) و (الحوار والصمت) و 
العدد الأريعون

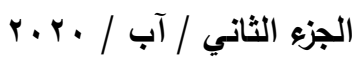

(الحزن والفرح) و( العاطفة والجمود)" (بنداري، د.ت :ص rAr)، وكل نلك يكون بفعل التوظيف لطبيعة الخط بصفته كعنصر من عناصر التكوين في الخط العربي. ـ -اللون : يعتبر اللون من العناصر الأساسية الداخلة في تكوين الخط العربي وتكوينات الفنون الأخرى لما له من أهمية في أظهار وتمييز التكوين شكلا ومضمونا بل في داخل التكوين الواحد، لعني واللون في تكوين الخط العربي لا يخضع الى طبيعة محدة بل يعتمد الاعتماد الكامل على توظيفه من قبل الفنان، وعلى ما يتضمنه التعبير الذي يحمله الخط الذي يشكل محور العمل الفني ومن هنا نجد تتعدد وظائفه في بيان المعنى وإكماله فهو يحمل سمة المكمل للمقطع الجملي أو يمنل عنصرا جماليا يضفي على العمل رونقه مع الأخذ بالاعتبار النسبة والتتاسب من حيث الدلالة والتعبير " فالألوان الدافئة والمتمثلة بالالوان (الأحمر والأصفر والبرتقالي) تمنح الإنسان الإحساس بالفرح، وتبعث فيه الحيوية والنشاط ، والألوان الباردة المتمثلة بالألوان (الأزرق والبنفسجي والأخضر) تهدى النفس وتريح الأعصاب وتصيبه أحيانا بالحزن..فوصف القلب الطيب بأنه ابيض... وأيضا اتخذت الحمامة البيضاء رمزا للسلام...وأطلق التسميات المستمدة من الألوان على كثثر من المناطق والمدن والأنهار

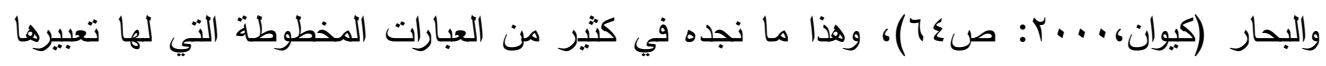
الخاص سيما الآيات القرآنية فتجد النص المكتوب تبشير بخير له من الألوان ما يميز ذلك وتجد اخرم اهو يعبر عن الحزن ..وهكذا فاللون في تكوين الخط العربي عنصر جماليا وتعبيريا وليس دلالة فعليه عن الأشكال الموضوعة والمتمنلة بالحروف والكلمات والعبارات ، وقد يوظف بهذا الشكل في فضاء أو المساحات أو الفراغات التي تتضمن المقطع الجملي للخط. ه -المساحة أو الفراغ في التكوين القني الخط العربي : ونقصد بالمساحات أو الفراغ في التكوين الفني للخط العربي هو ما يحيط بالثكل الفني للخط أو الوحدة الفنية كعنصر سوى أكان حرفا أم كلمة أم مقطع جملي، والمساحات في الخط العربي أو الفراغ قد يكون مجرد فراغ يمكن ان نصطلح عليه بالمساحات أو قد يكون فضاء و يرجع ذلك الى طبيعة التشكيل الذي يصيغه الخطاط من خلال حروفه أو كلماته أو جمله لان الخطاط قد يترك عبارته المخطوطة على طبيعتها وقد يشكل منها تشكيلا معينا قد يكون طيرا أو أنسانا أو أي شكل آخر وبذلك يمكن توظيف ذلك الفراغ كفضاء تبعا لهيئة وشكل الخط الكلي. ومن هذا نجد " أن لكل عنصر من عناصر العمل الفني إمكانيته، أهمها ان يؤدي تأثيرا كبيرا في

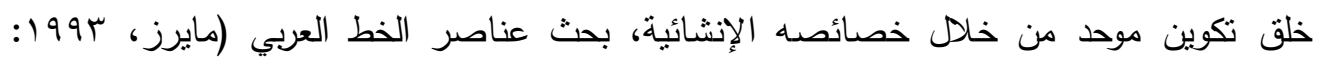
صه )كما يهيئ وحدة نسيجية منكاملة، ولذلك فأن جميع هذه العناصر والطريقة التي تم تشكيلها بها 
العدد الأربعون

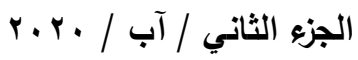

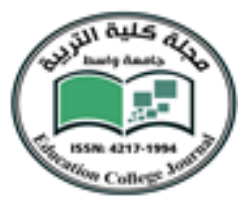

من خلال العمل الفني، تحرك فينا الإحساس بالمهارة اليدوية، والاستجابة البصرية وصولا الى عملية

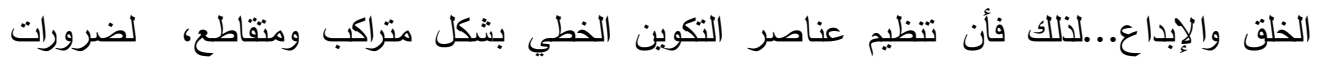

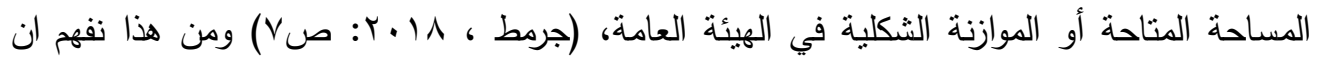
عناصر التكوين الفني للخط العربي شأنها شأن غيرها في أنواع الفنون الأخرى لابد من ان تستند على مبادئ أو أسس فنية أو أحكام جمالية أولية كأساس لتتظيمها ومن هذه الأسس (كالتوازن

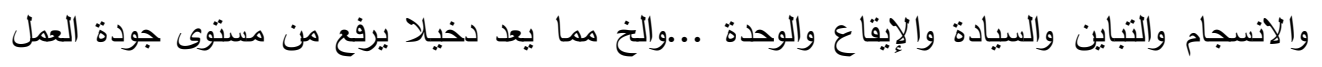
الفني وتماسكه ليؤدي الغرض الفني الذي أعد من اجله. أنماط التكوين القني للخط العربي للتكوين الفني في الخط العربي أنماط مختلفة نمنل طبيعة ترتيب العناصر الداخلة في تكوينه أي ما يؤكد الصفة الغالبة في نشكيل عناصره، لتجعل منه نكوينا فنيا ذو نمطا محددا ويرجع ذلك الى رؤية الفنان وذوقه في كيفية وضع عناصر عمله الفني وهذا لا يعني ان الفنان حرا في اختياره لذلك النمط من غيره، وإنما ذلك تقتضيه الضرورة الفنية في كافة أبعادها، وتعدد هذه الأنماط هو ما يعكس مرونة المادة التي يتم تشكيلها ووضعها في قالب فني ينسجم مع كل معطياتها وهذه الأنماط كلاتي: 1 -النمط الهرمي (المثلث): و يتم في هذا النوع من التكوين ترتيب أو تتظيم العناصر أو الوحدات بشكل هرمي ،"ويثير هذا النوع من التكوينات أحساسا بالرسوخ، والثبات بقوة درامية يتعذر أن يثيرها أي نكوينا أخر ...وتتزايد هذه الأحاسيس الدرامية حين تتكرر هذه المنلثات وتتراكب بعضها فوق بعض هض

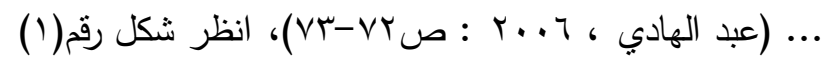

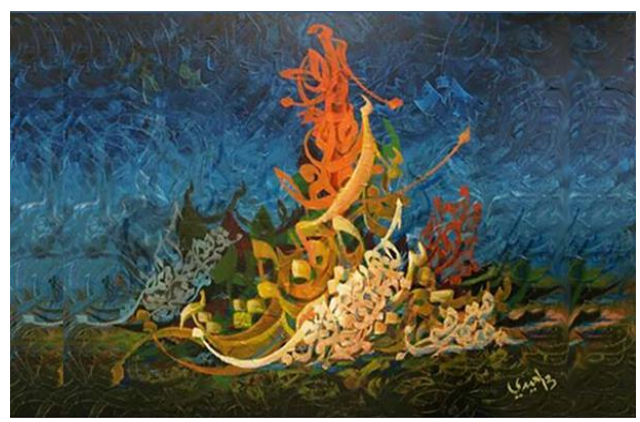

شكل رقم (1) - (1) - (1) 


$$
\begin{aligned}
& \text { العدد الأربعون }
\end{aligned}
$$

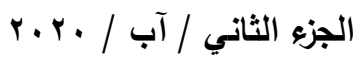

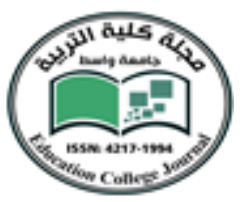

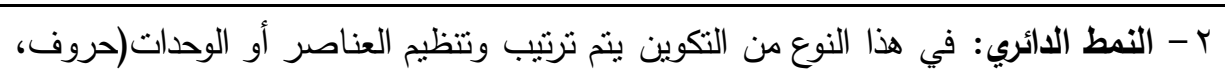

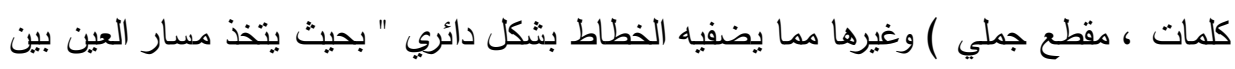

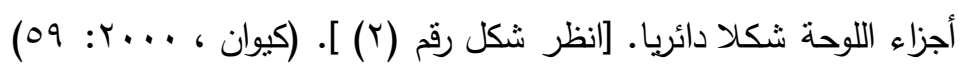

شكل رقم (r) (r) (1)

r - النمط الأفقي: هو النكوين الذي تكون فيه الوحدات أو العناصر منظمة بشكل أفقي والتي ترمز

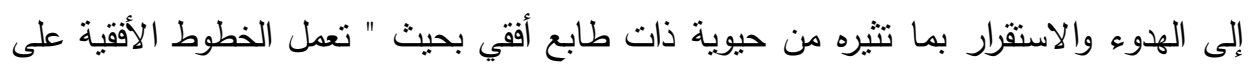

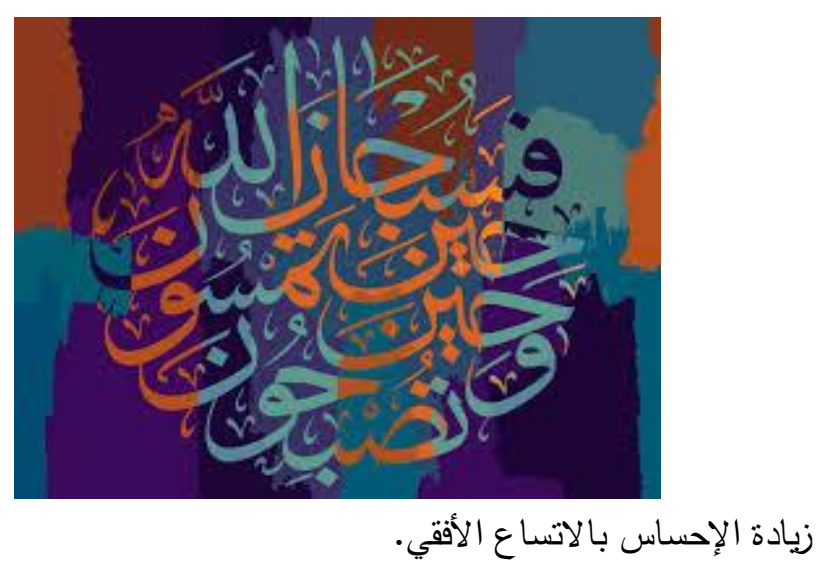

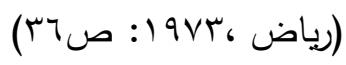

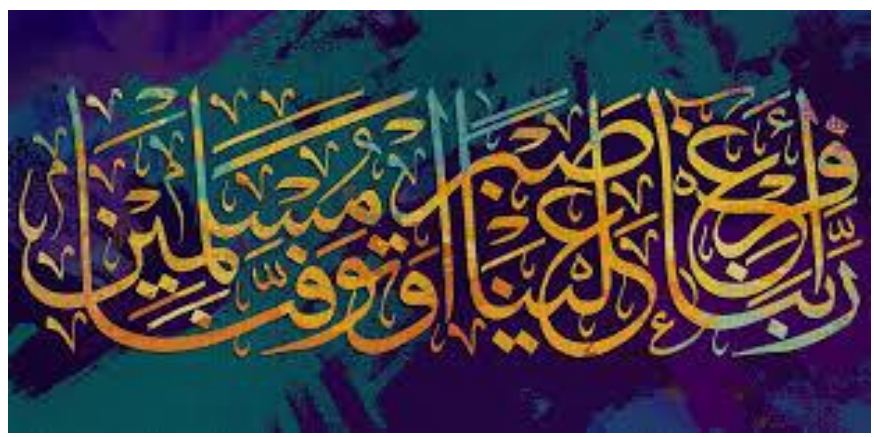

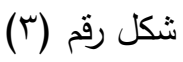




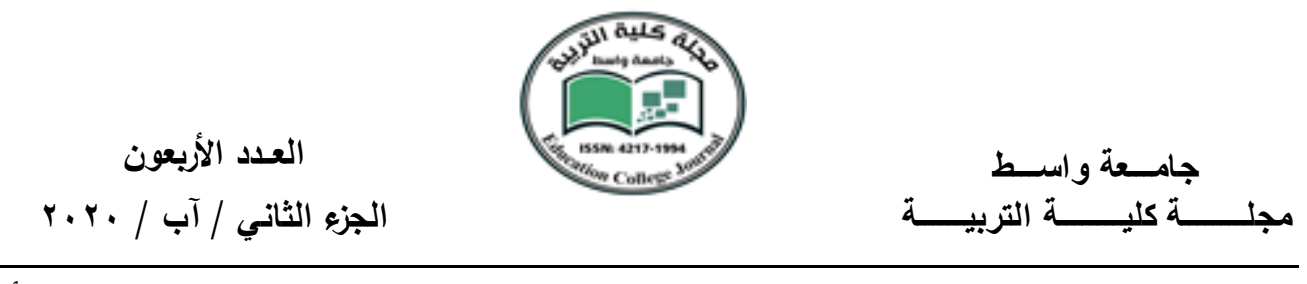

ع -النمط العمودي: ويتم في هذا النوع من التكوينات وضع العناصر التي تمنل سيادة العمل الفني أو

العناصر الرئيسية والثانوية منها بشكل رأسي شاقولي أنظر شكل رقم

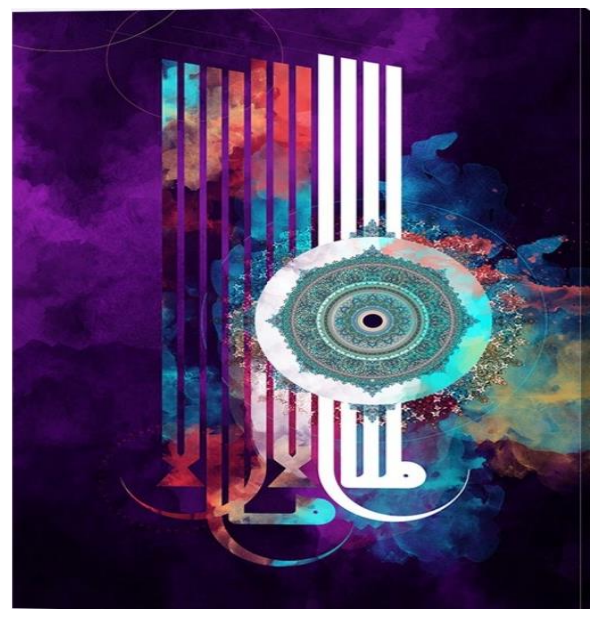

شكل رقم (乏)

0- - النمط الإثعاعي: وهو التكوين الذي تكون فيه السيادة للخطوط الراسية المائلة المنالاقية في

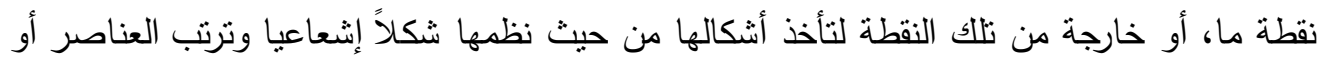
الوحدات التشكيلية في هذا النوع من التكوين في جميع الاتجاهات بحيث تنطلق من نقطة واحدة

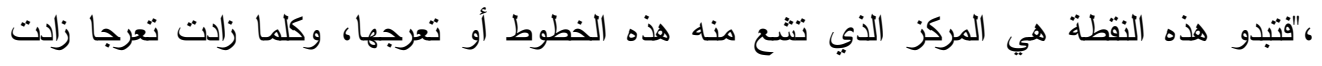

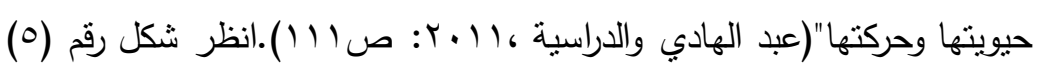
شكل رقم (0)

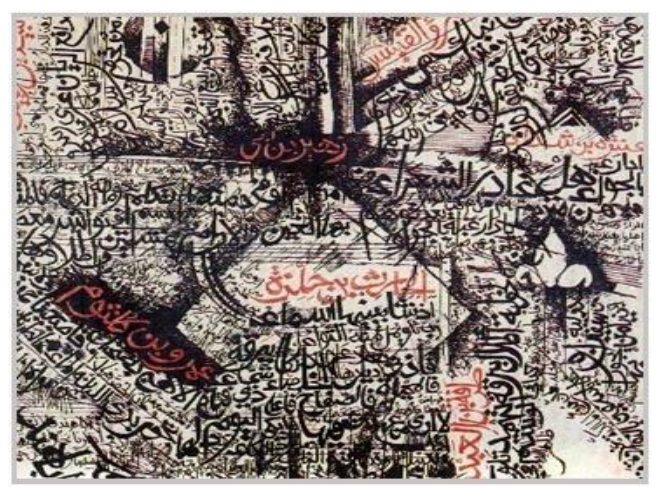




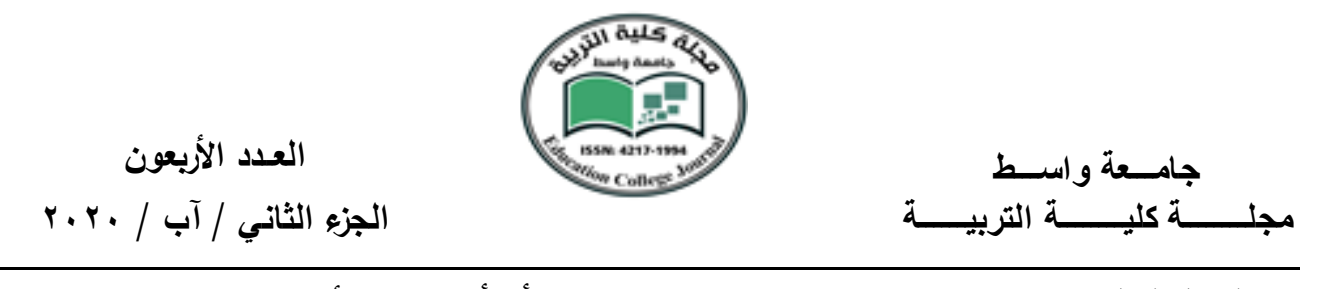

ج-النمط القطبي: وهو التكوين الذي يتم به "وضع شكلين أو أكثر من الأشكال المتقابلة توجد بينها

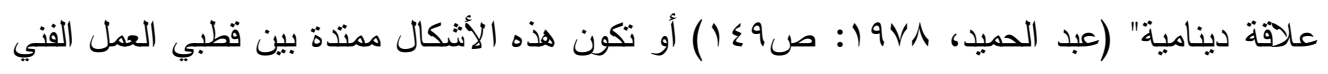

(7) أنظر شكل

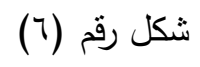

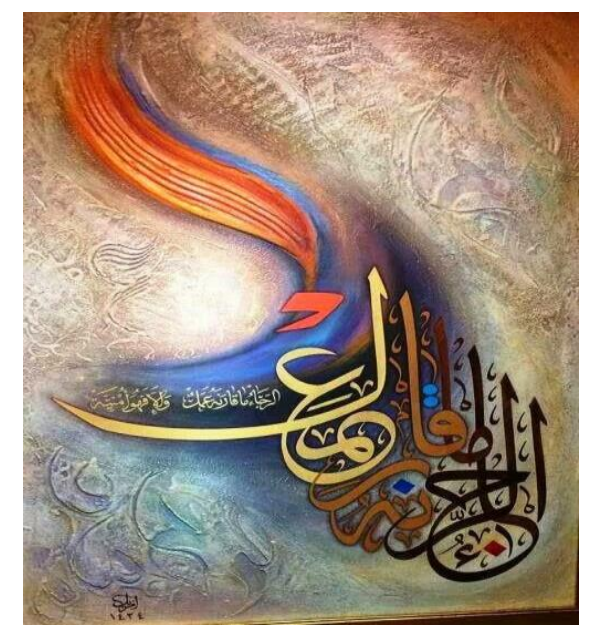

- - النمط الحر الانتشاري: وتكون فيه الوحدات موزعة بطريقة متجانسة ومنتظمة دون مركز إثعاع

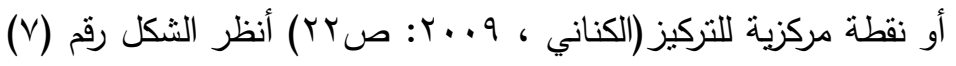

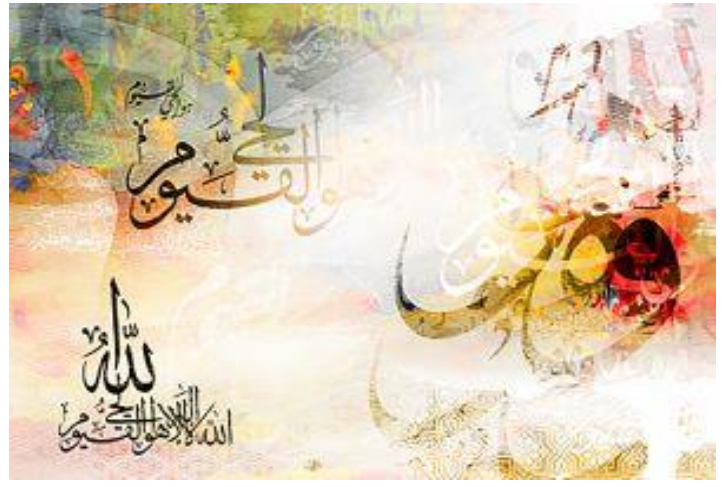

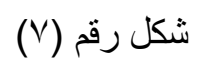


العدد الأربعون

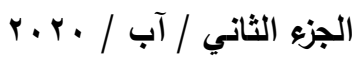

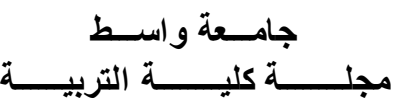

هو إثكال حروف الكتابة العربية التي تظهر في صورة جميلة ومنظمة، وكانت تسمي في السابق بالأقلام، وتخضع لقواعد وبنسب هندسية يلتزم بها الخطاط، وأنواعه كثيرة منها (الكوفي،

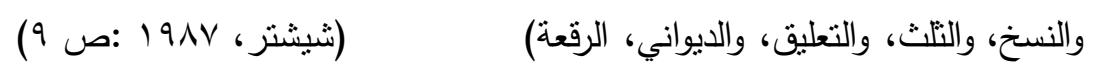
وعرف (العاني، 1990 ) الخط بأنه :فن لرسم الحروف الهجائية، والتعبير عن الشكل والمضمون بأصول، وقواعد هندسية زخرفيه تشكيلية مخصوصة في كتابتها .

(العاني، 1990$)$

وما قدمته الدراسات العلمية الحديثة، أن العرب قد أخذوا طربقتهم في الكتابة قبل الإسلام من بني عمومتهم الأنباط، وهم عرب أيضًا ـ واتخذ الخط الذي اقتبسه العرب عنهم عدة تسميات منها :، الخط الحيري، الخط الأنباري ، الخط المدني والخط المكي .

\section{(الجبوري:199)}

لقد سمى العرب الخطوط العربية نسبة إلى المدن التي وردت منها، وباستقرار الخط مثنا في مكة والمدينة عرف باسميهما بالخط المكي و الخط المدن، ولما انتقل مركز النشاط السياسي والمتمنل بالخلافة إلى العراق في خلافة علي ابن أبي طالب (عليه السلام) ، انتقل معه الخط المكي والمدني مدينة البصرة والكوفة وعرفت هناك في بادئ الأمر بأسماء المدن العربية الهامة التي صدرت عنها، ثم أولى الكوفيون الخط عناية كبيرة فعموا على تجويده وتحسينه فتميز عن الخط الحجازي وغلب

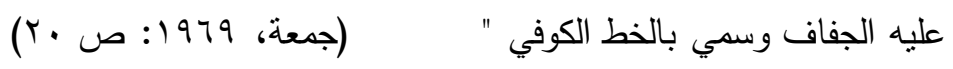
وفي القرن الثالث الهجري و لما الخطوط كثرت أعدادها وتتوعت أشكالها دعت الحاجة إلى تركيز أنواعها، وتصفية المتنسابه منه، والاقتصار على أوضحها وأجملها، وقد قام بذلك الخطاط الوزيرالمعروف ابن مقلة حين نسب الخطوط إلى نسب هندسية ثابتة، ثم حدد هذه الأنواع واستخلص منها أنواعًا ستة أخرى هي خط التلث وخط النسخ والتواقيع والريحان والمحقق والرقاع، ثم جاء بعده ياقوت المستعصدي المنوفى سنة 698 م فأجادها أيضا إجادة تامة ومما لا شك فيه إن اختصار

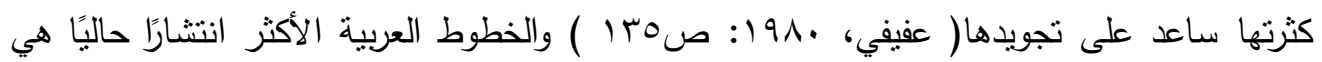
الخط ( الكوفي ، الديواني، الرقعة ، النسخ، الفارسي ). 


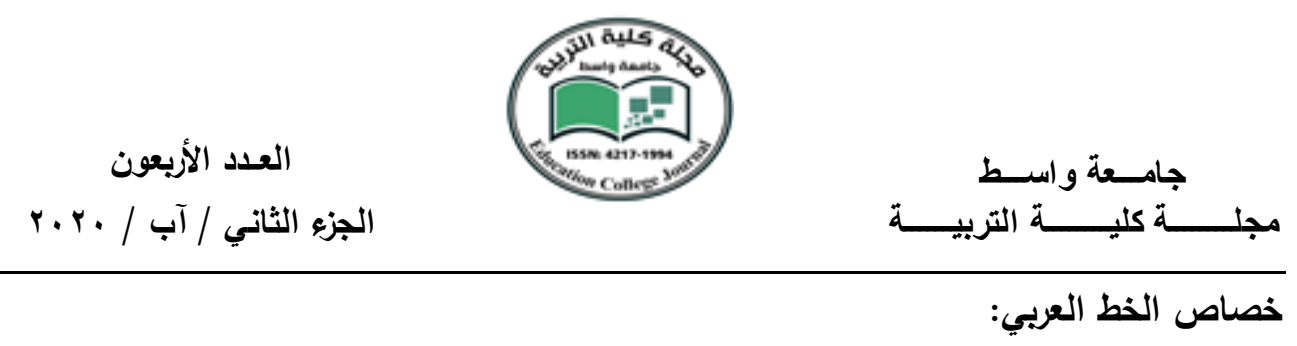

ويتميز الخط العربي بمجموعة من الخصائص) المتميزة والمنفردة عن مثيله من أنواع الخط منها ما بلي :

ا -الأصالة : وهى تعنى التأكيد على الهوية و التراث، حيث تكمن روحانية تلك الحروف الى كونها لغة القران الكريم وكفى بها شرفا أن نكون الصورة الأصيلة للحرف والكلمة هي مردود من التقديس لترتيل كلام رب العالمين.

r-الطلاقة : ونقصد بها تنوع جماليات الخط العربي لما يحويه من نتوع في الحجم ، والنوع والشكل، حتى النمط الواحد للخط يحتوى متتوعا كبي ا ر، فالخط الكوفي به الهندسي الذي يللل على التجريد

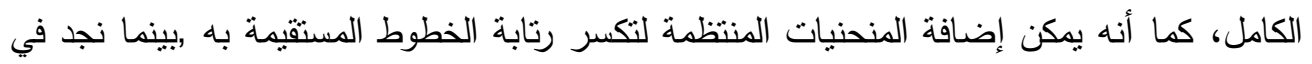
الخط الديواني كامل الحرية للتشكيل. ب-المرونة : لازال عطاء الخط العربي لما لا نهاية لصور النشكيل هو من دلالات المرونة العالية له .حتى أن بعضهم عدد أساليب تحوي ا رته واعتبروها أنواعا ثم حصرها إلى ثمانين نوعا . ع -الطواعية : يتميز الخط العربي بطواعيته لكل مساحة ،أو شكل، أو هيئة رحيث يمكن كتابة اللفظ وهئ بذات الخط داخل هيئة مربعة أو مستديرة أو مسدسه ضيقة أو واسعة مع إمكانيات تغيير أوضاعه تبعا للالالة المقصودة وقابلية الحرف للمد والاستدارة والبسط واللين والصعود والنزول. ( بنداري، د.ت: ص (V^) 


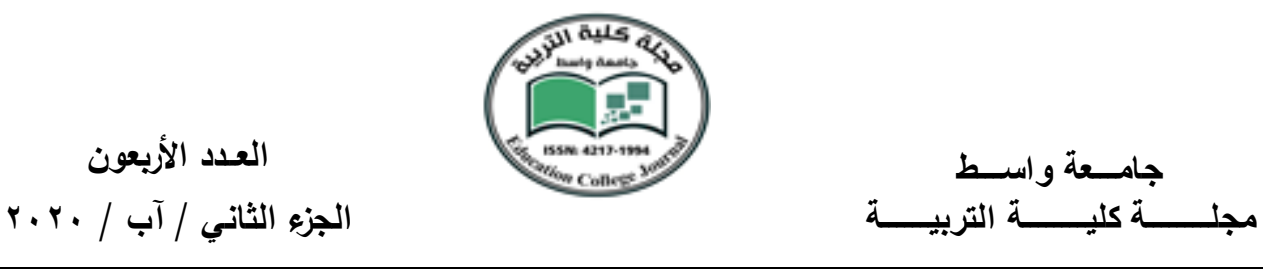

الفصل الثالث/ منهجية البحث واجراءاته

أولا:مجتمع البحث:

شمل مجتمع البحث النتاجات الفنية المنجزة لطلبة المرحلة الثانية في قسم التربية الفنية /كلية التربية

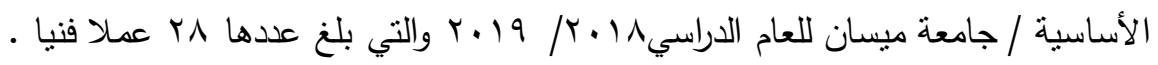
:ثانيا:عينة البحث :

لقد تم اختيار مجمل الإعمال الفنية للخط العربي كعينة للبحث والتي بلغت (r^) في أطار مجتمع البحث وبشكل قصدي لما يمكن ان تحققه من هدف البحث . ثالثا:منهجية البحث:

أعتمد الباحث المنهج الوصفي التحليلي في استقراء عينة البحث وتحليلها. أداة البحث : اعتمد الباحث (الملاحظة) أداة لبحثه معتمدا بذلك على (استمارة تحليل) في ملاحظة النتاجات لتحليلها مستمد معلوماتها من أدبيات الإطار النظري ومؤشراته.

الصدق : لغرض تحقيق صدق استمارة التحليل ، عرض الباحث هذه الاستمارة على مجموعة من الخبراء المختصين' ، وتم لاحقا تعديلها في استمارة مقننة جديدة.

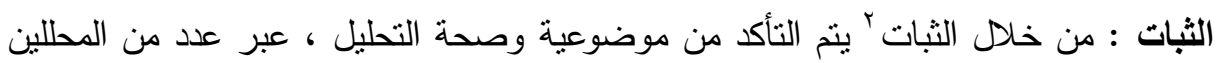

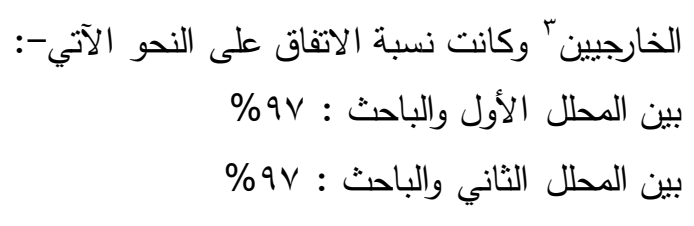
: إجراءات البحث

تحليل عينة البحث وفق ما حده الباحث من فقرات خاصة بطبيعة أنواع التكوين الفني والتي أثار إليها تفصيلا في الإطار النظري للبحث والتي حددها الباحث وفق الاستعانة بالخبراء كما في ملحق وهي كما في ملحق رقم (r) • اذ وجد الباحثان ان معظم الأعمال الفنية المنجزة للطلب في

' أ.د صالح أحمد الفهاوي/ كلية الفنون الجميلة/ جامعة بغداد .. أ.د حسين محمد الساقي/كلية التربية الأساسية/ الجامعة المستنصرية.

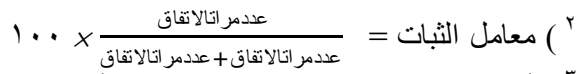
ץ ) أ.م.د سهاد جو اد الساكني/كلية التربية الأساسية / الجامعة المستتصرية.. أ.م.د فاطمة محمد عبد الله / كلية التربية الأساسية / الجامعة المستنصرية 
العدد الأربعون

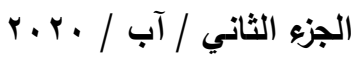

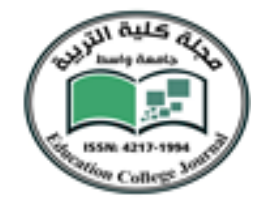

المرحلة الثانية إعمالا ذا تكوينات جيدة من الناحية الثكلية وطبيعة نوظيف وترتيب العناصر بشكل

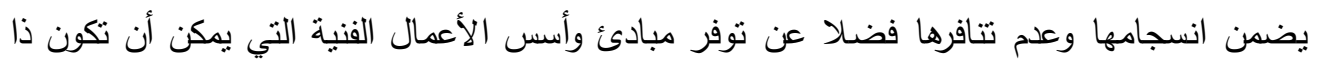

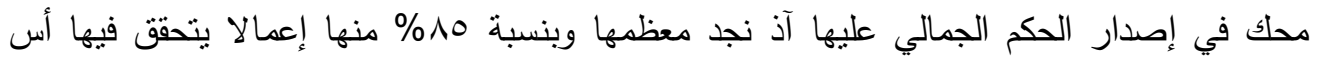
التوازن وهو شرط تحقيق الاستقرار النفسي وكنلك توف عنصر السيادة والمتمنل بالعبارات الخطية

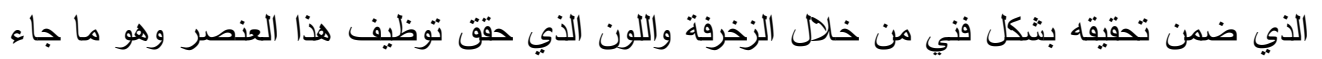
بالنسبة الكلية للإعمال الفنية . . 1\% وأن تتبع الباحثان عن طبيعة ووحدة العمل الفني وتكامله الثكلي

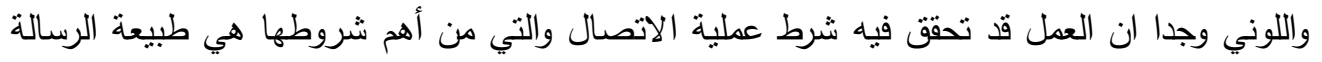

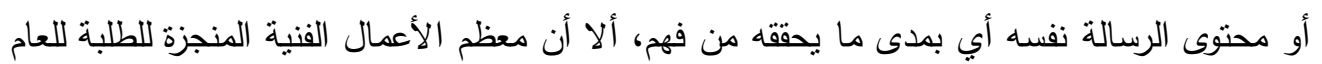

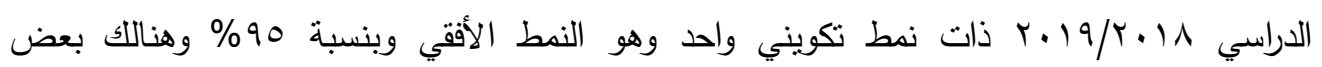

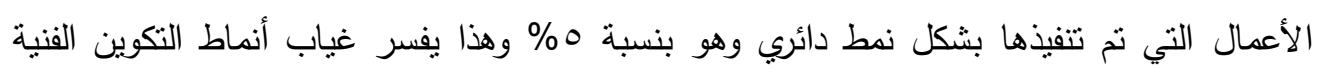

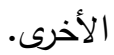

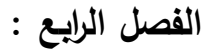

\section{أولا: النتائج ومناقشتهها:}

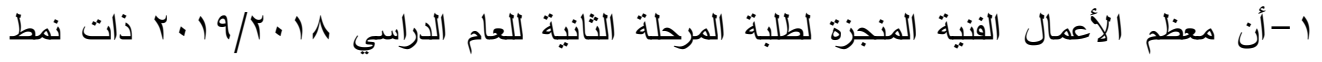

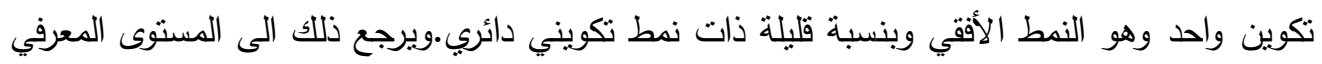
الضعيف وعدم تلقي المعلومات الوافية حول موضوع أنماط النكوين الفني الرئيسية الأخرى (النكون الثاقولي، والنكوين القطبي، والنكوين الهرمي والتكوين الدائري، والتكوين الانتثاري (الحر) ) ).

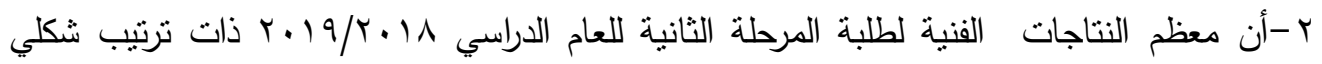
يتحقق فيه نظام التكوين الفني الموحد. ثنانياً: الاستتتاجات:

توصل الباحث من خلال عرض النتائج إلى الاستتناجات الآثية:

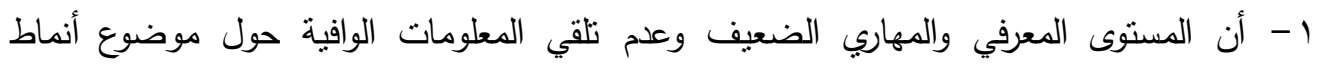
النكوين الفني الرئيسية الأخرى (النكون الثاقولي، والتكوين القطبي، والتكوين الهرمي والتكوين الدائري،

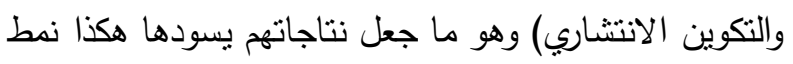


العدد الأربعون

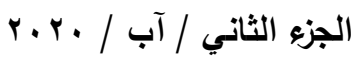

r- أنماط النكوين الفني كمهارة تعليمية تعتمد بشكل أساسي على الرؤية البصرية وعلى طريقة تقديمه من قبل التدريسي، مما يدعو ذلك الى الحاجة الى استخدام الطرق المناسبة في توظيفه كمتغير

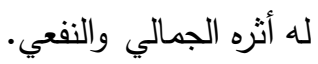

ثالثاً:التوصيات : بناءً على ما نوصل أليه الباحث من استتناجات فإنه يوصي بما يأني :

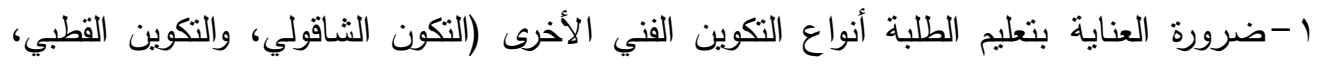
والتكوين الهرمي والتكوبن الدائري) لضمان التنوع والتشكيل لتحقيق الجمال الفني للخط العربي ويكون التئين ذللك من خلال إضافة النكوين الفني في الخط العربي كمفردات تتضمن مفهوم التكوين وعناصره والأسس التي يقوم عليها و أنماط التكوين وكذلك من خلال اختبار طرائق التذريس المناسبة لذلك.

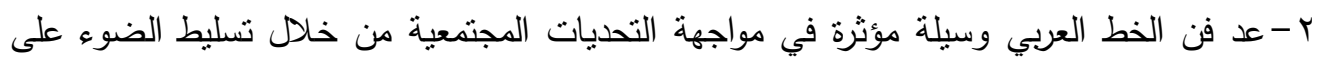

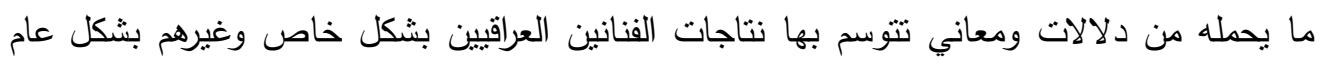
بهذا المجال لاسيما المجال التربوي من خلال طرحة بأثكال وأنماط فنية مختلفة.

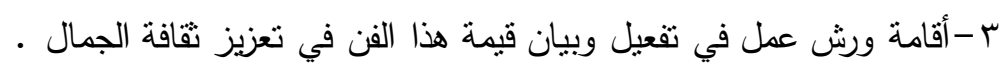
لايعاً: المقترحات: في ضوء ما توصل اليه الباحث من نتائج واستتناجات يقترح أجراء الدراسات الآتية:

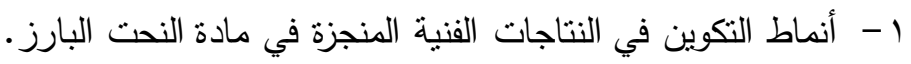
r - أثر طريقة الننذجة في النكوين الفني لنتاجات طلبة المرحلة الثانية في مادة الخط العناء العربي.

\section{المصادر}

ا - بنداري، ياسر سعيد محد، الأثر الفاعل للثكل والمضمون لفن الخط العربي في علاقته بوضع أطر منهجية لنظم

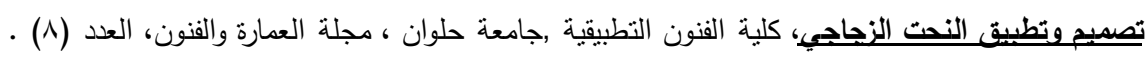

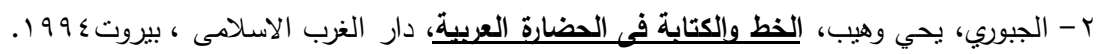

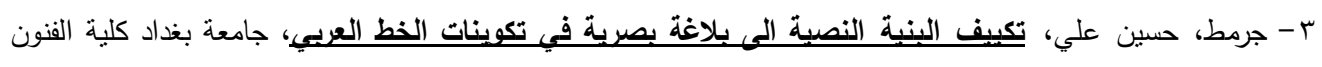

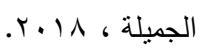
ع - جمعه، إبراهيج، دراسة في تطور الكتابات الكوفية على الأحجار في مصر في القرون الخمسة الأولي للهجرة، 


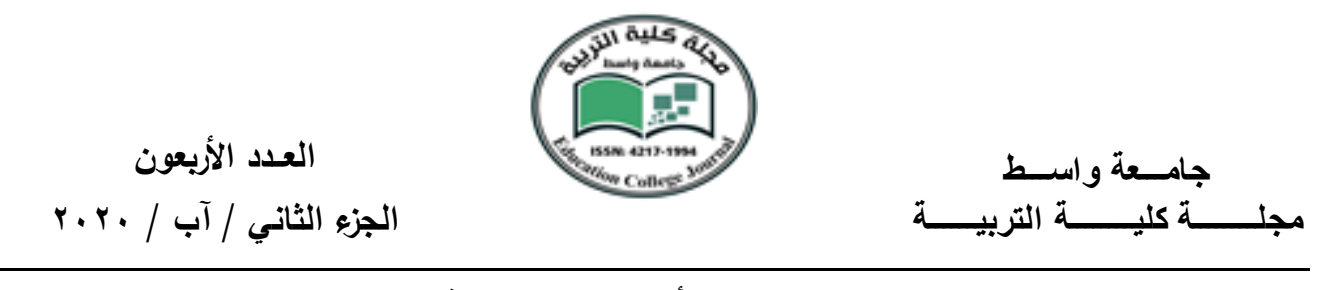

0- الجميلي، عامر عبد الله، مقال / النقاط شكالها وأسالييها ومواضعها في الخط العربي ، مقال منشور في موقع

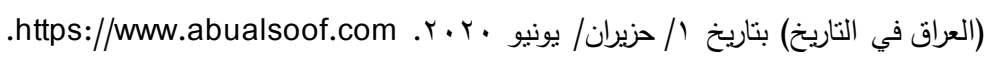

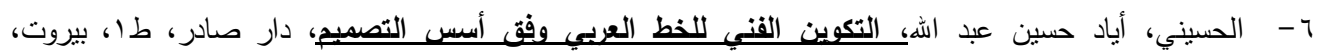

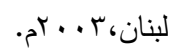

191. • - V الخطيبي، عبد الكبير، ديوان الخط العربي، ت- برادة، دار العودة، بيروت

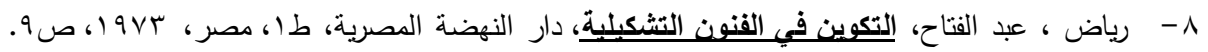

9 - رياض، عبد الفتاح، التكوين في الفنون التثكيلية، الناشر دار النهضة العربية، طا، القاهرة، مصر بVو ا. • 1 - الزفتاوي، محمد ابن احد، منهاج الصابة في معرفة الذطوط والات الكتابة، تحقيق هلال ناجي، مجلة مورد، مج

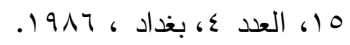

11 - سنولنيز ، جيروم ، النقا الفنيـ - دراسة جمالية وفلسفية ، ترجمة فؤاد زكريا ، ، مطبعة عين شمس ، القاهرة، ع 9 1.

r ا - شيشتر، عبد المحن حسين عبد الرضا، الوظيفة الزخرفية للحرف العربي كمخل تجريبي لتريس التصميم فيـ

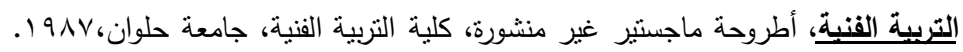
با - العاني، عبد المنعم خير، تصميـ برنامج للابداع في الخط العبيـ الكوفي، أطروحة دكتوراه غير منشورة، كلية

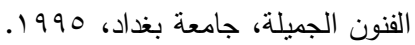

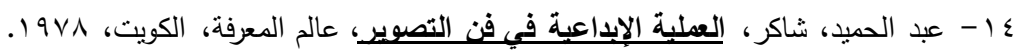
10- عبد الهادي ، عدلي محمد ، الدرايسة ، محمد عبد الله ، نظرية اللون (مبادئ في التصميم) ، مكتبة المجتمع

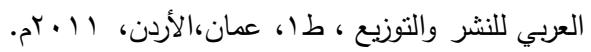
1 1 - عبدالهادي، عدلي محمد، مبادئ التصميع واللون، مكتبة الهتمع العربي للنشر والتوزيع،طا، عمان - الأردن، IV الكويت، . 191.

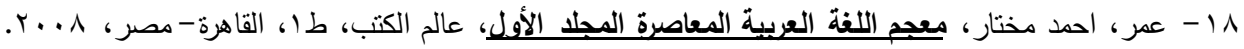
9 ا - فريدريك، مالنز ، الرسبمكيف نتذوقه عناصر التكوين ، ت :هادي الطائي، وزارة الثقافة والإعلام، دار الثؤون التقافية، ط 1، بغداد، بـ199

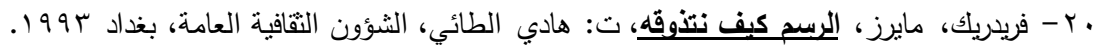

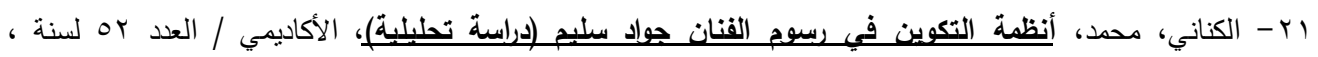


العدد الأربعون

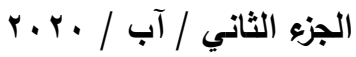

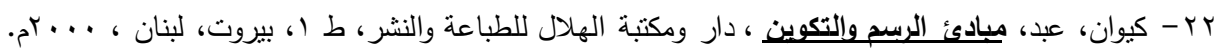

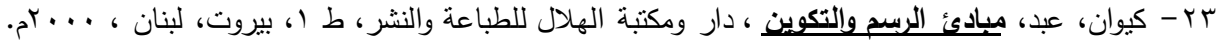

\section{ملحق رقم (1)}

استمارة تحليل نتاجات الطلبة في مادة الخط العربي

\begin{tabular}{|c|c|c|}
\hline خصائصه & نمط التكوين & $ت$ \\
\hline تركون فيه الوحدات التي تشكل العمل الفني أو العناصر منظمة بشكل أفقي والتي & الأفقي & 1 \\
\hline توالثانونية فنها الوحدات أو العناصر التي تنثل سيادة العمل الفني أو العناصر الرئيسية & ألعامودي & $r$ \\
\hline تكون فيه الوحدات أو العناصر مرنبة بشكل هرمي وممكن تتكرر هذه المتلثات & الهزمي & $r$ \\
\hline تكون فيه الوحدات أو العناصر مرتبة ومنظمة بشكل دائري " بحيث يتخذ مسار & الدائري & $\varepsilon$ \\
\hline 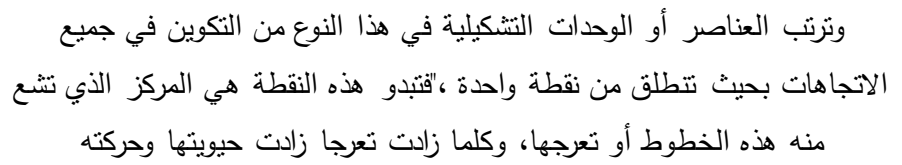 & الإشعاعي & o \\
\hline وتكون فيه الوحدات أو العناصر منقابلة بين طرفي العل الفني وبينهما علاقة & القطبي & 7 \\
\hline تكون فيه الوحدات موزعة بطريقة متجانسة ومنتظمة دون مركز إثعاع أو نقطة & الانتشاري & $v$ \\
\hline
\end{tabular}




$$
\begin{aligned}
& \text { العدد الأربعون }
\end{aligned}
$$

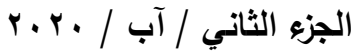
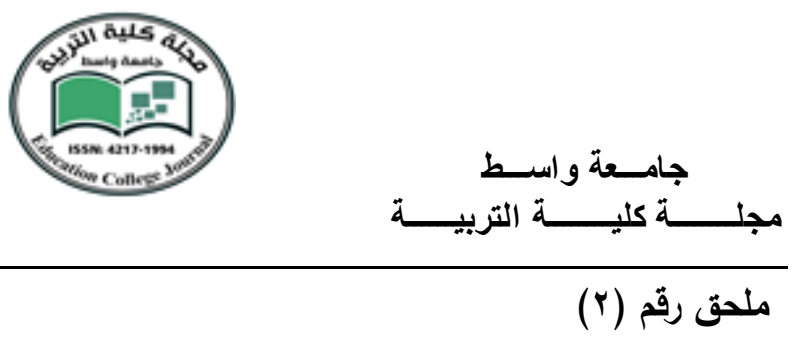

نماذج من نتاجات الطلبة
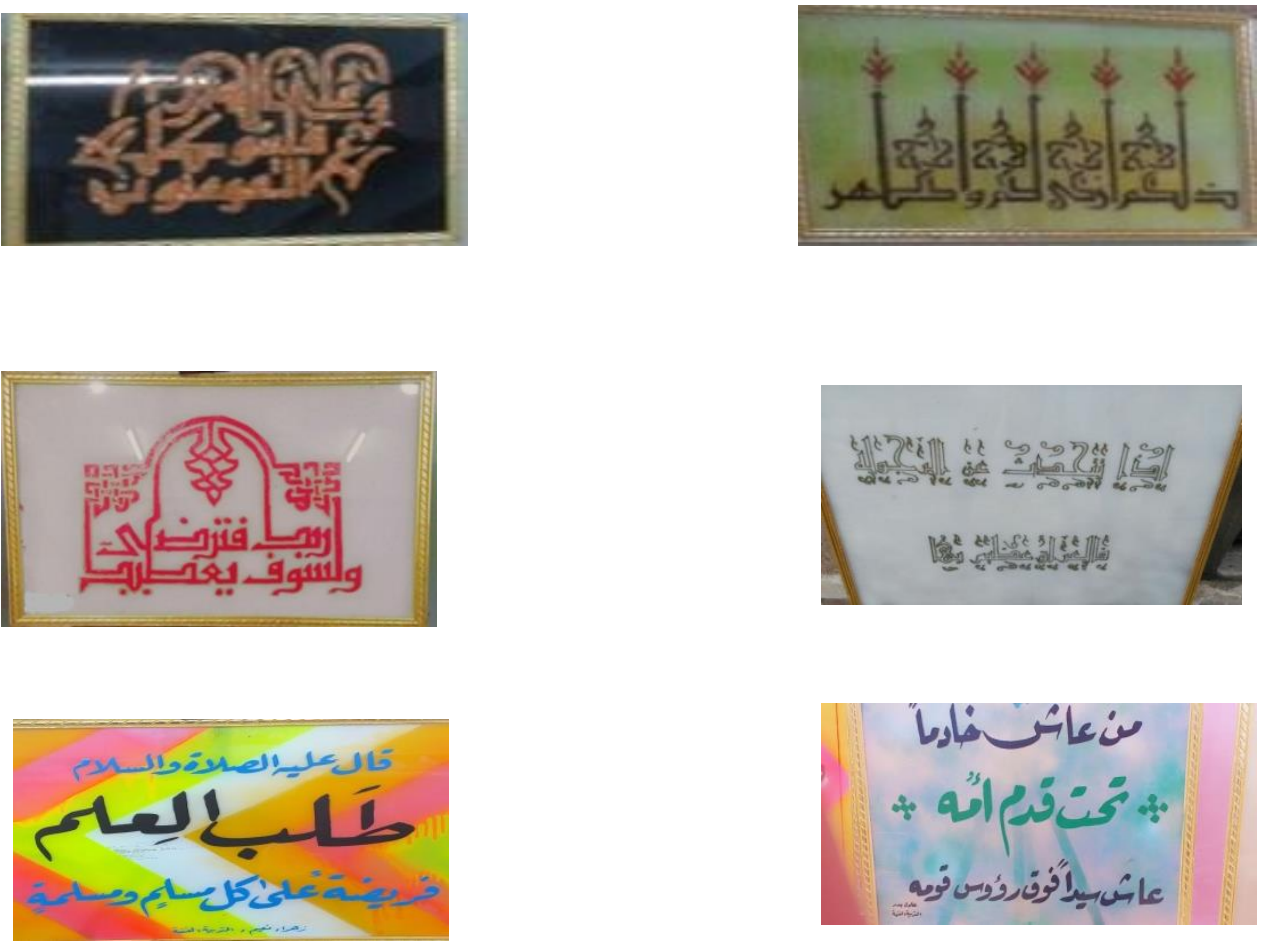